\title{
Topology and control algorithms for a permanent magnet synchronous motor as a part of a vehicle with in-wheel motors
}

\author{
A.S. Lutonin ${ }^{1}$, J.E. Shklyarskiy ${ }^{2}$ \\ ${ }^{1}$ Department Of Information System And Computing Technologies, Saint Petersburg Mining \\ University, St. Petersburg, Russia \\ ${ }^{2}$ General Electric Department, Saint Petersburg Mining University St. Petersburg, Russia
}

\begin{abstract}
This article describes an electric drive system's topology with a permanent magnet synchronous motor for a wide speed range applications. Topology consists of a synchronous motor with permanent magnets (PMSM) and two inverters connected to the beginnings and to the ends of the PMSM's stator windings. The first inverter is connected to a storage battery, while the other one to a floating bridge capacitor, which acts as a back-EMF compensator. The article proposes electric drive system topology and its control algorithm. Simulation modeling was implemented by the MATLAB/Simulink software package. Simulation results shows that the proposed electric drive system, in comparison with the standard topology with a «star» stator windings connection, is able to increase the maximum speed of PMSM in the field weakening mode by $17 \%$. The maximum achievable torque on the rotor shaft at the maximum speed of the PMSM motor was increased by $16.6 \%$. Also, developed topology allows to increase the speed range in the constant torque mode by $34 \%$.
\end{abstract}

\section{Introduction}

At present, in-wheel motors usage, in the composition of vehicles, is a promising solution due to the following advantages: the rejection of mechanical energy converters (gearbox, differential, constant velocity joints), which contribute to additional losses in the system, reducing the final mass of the vehicle, its distribution and, consequently, increasing the efficiency of the system [1-3]. However, the main disadvantage of this solution is the need to operate the electric motor in a wide range of speeds while maintaining high values of torque on the shaft, which makes it difficult to implement in vehicle powertrains. Thus, electric motors with parameters which meets the following requirements, can be used for operation as part of in-wheel motor: high torque at low speeds; wide speed control range; high coefficient of power density. Electric motors which corresponds to mentioned above criteria are presented by the following types: asynchronous electric motor [4,5], permanent magnet synchronous motor [6,7]; brushless DC motor [8]; reluctance motor [9]. Based on the comparative analysis carried out in work [10], the permanent magnet synchronous motor (PMSM) is the most suitable type of electric motor forin-wheel motors. Both domestic and foreign authors have developed systems designed to control PMSMs at a wide range of speeds. So, in articles [11], algorithms of V/F control of a PMSM were considered. 
Papers [12-16] are devoted to the development of field-oriented vector control and direct torque control. In [17-19], the possibility of weakening the magnetic field of the PMSM to achieve speeds above the nominal values was considered. In articles [20-22], a topology with the connection of an additional inverter to the ends of stator windings to expand the range of motor operating speeds was proposed. The use of such a connection scheme provides for: extending the speed range of the PMSM by compensating the counter-EMF of the electric motor [23]; the possibility of backup switching to the "star" mode in case of failure of one inverter when feeding the auxiliary inverter from the battery or from the common with the main converter' source [24]; availability of additional power source with a possibility of its reservation [25]; possibility to increase a voltage level applied to the PMSM in case of absence of both boost converters and additional power sources [26,27]; decrease in amplitude of current ripple [28]. Papers [29] consider the use of a floating bridge capacitor as a secondary energy source for the topology with two inverters. Based on a comparative analysis of the use of different energy sources to power the auxiliary inverter, presented in [30], the PMSM topology using a floating bridge capacitor is the most promising solution for use in a vehicle, because, in comparison with topologies using a single energy source, does not contribute to zero sequence currents, and in comparison, with systems where the auxiliary inverter is powered from an additional accumulator. In the papers [31,32], the peculiarities of selecting inverters for electric drive systems were considered. In the paper [33], the influence of the electric drive system on the source of supply voltage was evaluated. At the same time, no works have so far considered the electric drive system using permanent magnet synchronous motors with open-endstator winding and a floating bridge capacitor as a part of a vehicle using in-wheel motors.

\section{Problem statement}

For full-fledged use of PMSM topology with an open-end winding and a floating bridge capacitor in the vehicle, it is necessary to develop a control algorithm of the abovementioned electric drive system for use in a wide speed range, as well as to conduct a comparative analysis of the proposed topology and its control algorithm in comparison with the technical solutions already used for such purposes. Thus, the purpose of the study, the results of which are presented in the article, is to develop a control algorithm for a PMSM with open-endstator winding and a floating bridge capacitor in a wide range of speeds.

\section{Research methodology}

The equations for the PMSM with respect to the rotating $d$-q coordinate system are three basic equations which, according to [34,35], can be express ed by formulas $(1-3)$ :

$$
\begin{gathered}
U_{m d}(t)=U_{M I d}(t)-U_{C I d}(t)=R I_{d}(t)+L_{d} \frac{d I_{d}(t)}{d t}-\omega_{m e}(t) L_{q} I_{q}(t) \\
U_{m q}(t)=U_{M I q}(t)-U_{C I q}(t)=R I_{q}(t)+L_{q} \frac{d I_{q}(t)}{d t}-\omega_{m e}(t) L_{d} I_{d}(t)+\omega_{m e}(t) \psi_{p m}, \\
T_{e}(t)=\frac{3}{2} p\left(\psi_{p m}+\left(L_{d}-L_{q}\right) I_{d}(t)\right) I_{q}(t)
\end{gathered}
$$


where $U_{m d}(t), U_{M I d}(t), U_{C I d}(t)$ are voltage levels at the ends of the PMSM windings, battery, and capacitor relative to the axis d; $U_{m q}(t), U_{M I q}(t), U_{C I q}(t)$ are the voltage levels at the ends of the PMSM windings, battery and capacitor relative to the axis q; $R_{s}$ is the stator winding resistance value; $L_{d}$ is the inductance value relative to the axis $\mathrm{d} ; L_{q}$ is the inductance value relative to the axis q; $\omega_{m e}(t)$ is the rotational speed of the electromagnetic field of the rotor; $\psi_{p m}$ is the flux linkage of permanent magnets of the PMSM; $I_{d}(t)$ is the PMSM current with respect to the axis $\mathrm{d} ; I_{q}(t)$ is the PMSM current with respect to the axis q; $T_{e}(t)$ is the PMSM electromagnetic torque; $p$ is the number of pole pairs of the PMSM.

The research methodology involves the study of the transients occurring in a synchronous motor with permanent magnets, an open stator winding, and a floating bridgecapacitor based on differential equations $(1-3)$ using simulation methods in the Matlab/Simulink software package.

\section{The control algorithm for a permanent magnet synchronous motor over a wide speed range}

Considering a PMSM operation in a wide speed range, it is necessary to determine the limit values of speed and torque on the rotor shaft, which are limited by the maximum allowable values of currents and voltages according to formulas $(4-5)$ :

$$
\begin{gathered}
I_{d}^{2}+I_{q}^{2} \leq I_{\max }^{2}, \\
U_{m d}^{2}+U_{m q}^{2} \leq U_{\max }^{2},
\end{gathered}
$$

where $I_{\max }$ is the maximum motor current; $U_{\max }=U_{d c} / \sqrt{3}$ is the maximum output voltage relative to the PMSM stator windings.

To carry out the calculations of the PMSM operation modes, as the equation of motor speed limitation as a function of voltage, equations (4 - 5) must be equated with equations (7 - 8), taking into account the following conditions: $d i_{d}(t) / d t=0 ; R \cdot i_{d}(t)=0 ; R \cdot i_{q}(t)=0$. The solution is the equation of the PMSM velocity limit ellipse from voltage (4):

$$
\omega_{m e} \leq \frac{U_{m \max }}{\sqrt{\left(L_{q} i_{q}\right)^{2}+\left(\psi_{p m}+L_{d} i_{d}\right)^{2}}},
$$

where $\omega_{m e}$ is the electric speed of the PMSM. 
Fig. 1 shows the limits of the PMSM operating characteristics, according to which the optimal current settings in the rotating coordinate system $\mathrm{d}-\mathrm{q}$, depending on the current and set values of torque and speed on the rotor shaft, can be divided into 4 main modes: MTPA, $\mathrm{FW}, \mathrm{MC}$, and MTPV. The diagram which is shown in Figure 1 was constructed based on the equations described below using the MATLAB software package. The diagram shown in Figure 1 was created by MATLAB software package using mentioned below the equations.

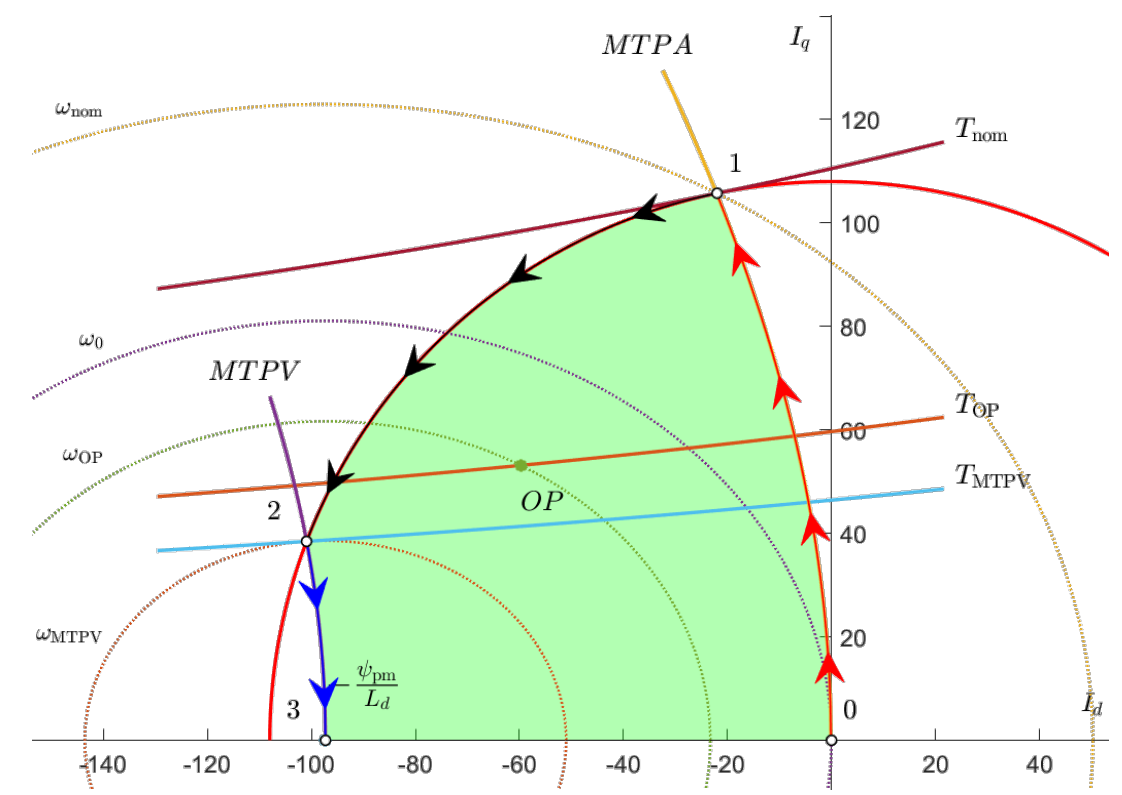

Fig. 1. Performance limits of the PMSM

The MTPA (maximum torque per ampere) mode is used when it is possible to achieve the highest possible ratio of output torque on a shaft with the minimum supply current in the speed range from $0 \mathrm{rpm}$ to their rated value (in Fig. 1 the curve is marked with a red arrow); the MC (maximum current) mode is used when the motor's rated speed is exceeded in the case when the torque demand is equal or above the maximum allowable value (the curve is marked with a black arrow in Fig. 1); the MTPV (maximum torque per voltage) mode is optimal for deep field weakening when the MC mode is no longer optimal to achieve the necessary shaft torque values (the curve is marked with a blue arrow in Fig. 1); the FW (field weakening) mode is optimal in the speed range above the rated speed when the shaft speed and torque setting is below the limit values (the point family within the range marked with a green arrow).

The final system of equations for determining the stator currents in the rotating $d-q$ coordinate system in MTPA mode is expressed according to equations $(7-8)$ :

$$
\begin{gathered}
i_{d M T P A}=-\frac{A_{1}}{4}-\frac{\eta_{1}}{2}-\frac{\mu_{1}}{2} \\
i_{q M T P A}=\frac{2 T_{e} / 3 p}{\psi_{p m}+\left(L_{d}-L_{q}\right) i_{d M T P A}},
\end{gathered}
$$

where coefficients $\eta_{1}, \mu_{1}$ are expressed according to formulas $(9-13)$ : 


$$
\begin{gathered}
\eta_{1}=\sqrt{\frac{A_{1}^{2}}{4}-B_{1}+\gamma_{1}}, \\
\gamma_{1}=\frac{B_{1}}{3}+\sqrt[3]{-\frac{\beta_{1}}{2}+\sqrt{\frac{\beta_{1}^{2}}{4}+\frac{\alpha_{1}^{3}}{27}}}+\sqrt[3]{-\frac{\beta_{1}}{2}-\sqrt{\frac{\beta_{1}^{2}}{4}+\frac{\alpha_{1}^{3}}{27}}}, \\
\alpha_{1}=\frac{1}{3}\left(3 A_{1} C_{1}-12 D_{1}-B_{1}^{2}\right), \\
\beta_{1}=\frac{1}{27}\left(-2 B_{1}^{3}+9 A_{1} B_{1} C_{1}+72 B_{1} D_{1}-27 C_{1}^{2}-27 A_{1}^{2} D_{1}\right), \\
\mu_{1}=\sqrt{\frac{3}{4} A_{1}^{2}-\eta_{1}^{2}-2 B_{1}-\frac{1}{4 \eta_{1}}\left(4 A_{1} B_{1}-8 C_{1}-A_{1}^{3}\right)} .
\end{gathered}
$$

Coefficients $A_{1}, B_{1}, C_{1}, D_{1}$, in their turn, can be found in accordance with (14 - 17):

$$
\begin{gathered}
A_{1}=\frac{3 \psi_{p m}}{\left(L_{d}-L_{q}\right)}, \\
B_{1}=\frac{3 \psi_{p m}^{2}}{\left(L_{d}-L_{q}\right)^{2}}, \\
C_{1}=\frac{\psi_{p m}^{3}}{\left(L_{d}-L_{q}\right)^{3}}, \\
D_{1}=\frac{4 T_{e}^{2}}{9 p^{2}\left(L_{d}-L_{q}\right)^{2}} .
\end{gathered}
$$

For the MC mode, the current values $i_{d}, i_{q}$ are found according to equations $(18-19)$ :

$$
\begin{gathered}
i_{d M C}=\frac{-\psi_{p m} L_{q}+\sqrt{\left(\psi_{p m} L_{q}\right)^{2}-\left(L_{d}-L_{q}\right)^{2}\left(L_{q} I_{\max }^{2}+\psi_{p m}^{2}-\frac{U_{\max }^{2}}{\omega_{m e}^{2}}\right)^{2}}}{4\left(L_{d}-L_{q}\right)}, \\
i_{q M C}=\sqrt{I_{\max }^{2}-I_{d M C}^{2}} .
\end{gathered}
$$


The equations for finding the control currents in the MTPV mode are:

$$
\begin{gathered}
i_{d M T P V}=-\frac{\psi_{M T P V}+\psi_{p m}}{L_{d}}, \\
i_{q M T P V}=\frac{L_{q} \psi_{p m}-\sqrt{\left(L_{q} \cdot \psi_{p m}\right)^{2}+8\left(L_{d}-L_{q}\right)^{2}\left(U_{m} / \omega_{m e}\right)}}{4\left(L_{d}-L_{q}\right)}
\end{gathered}
$$

where $U_{m}$ is the current value of the voltage. The value $\psi_{M T P V}$ can be found by formula (22):

$$
\psi_{M T P V}=\frac{-L_{q} \psi_{m}+\sqrt{L_{q}^{2} \psi_{m}^{2}+8\left(L_{d}-L_{q}\right)^{2}\left(U_{m} / \omega_{m e}\right)^{2}}}{4\left(L_{d}-L_{q}\right)} .
$$

For the FW mode, the final writing of the system of equations for determining the stator currents in the rotating d-q coordinate system according to formulas $(23-24)$ :

$$
\begin{gathered}
i_{d F W}=-\frac{A_{2}}{4}-\frac{\eta_{2}}{2}+\frac{\mu_{2}}{2}, \\
i_{q F W}=\frac{2 T_{e} / 3 p}{\psi_{p m}+\left(L_{d}-L_{q}\right) i_{d F W}},
\end{gathered}
$$

where coefficients $\eta_{2}, \mu_{2}$ are expressed in accordance with equations $(25-29)$ :

$$
\begin{aligned}
& \eta_{2}=\sqrt{\frac{A_{2}^{2}}{4}-B_{2}+\gamma_{2}} \\
& \gamma_{2}=\frac{B_{2}}{3}+\sqrt[3]{-\frac{\beta_{2}}{2}+\sqrt{\frac{\beta_{2}^{2}}{4}+\frac{\alpha_{2}^{3}}{27}}}+\sqrt[3]{-\frac{\beta_{2}}{2}-\sqrt{\frac{\beta_{2}^{2}}{4}+\frac{\alpha_{2}^{3}}{27}}} \\
& \alpha_{2}=\frac{1}{3}\left(3 A_{2} C_{2}-12 D_{2}-B_{2}^{2}\right) \\
& \beta_{2}=\frac{1}{27}\left(-2 B_{2}^{3}+9 A_{2} B_{2} C_{2}+72 B_{2} D_{2}-27 C_{2}^{2}-27 A_{2}^{2} D_{2}\right), \\
& \mu_{2}=\sqrt{\frac{3}{4} A_{2}^{2}-\eta_{2}^{2}-2 B_{2}-\frac{1}{4 \eta_{2}}\left(4 A_{2} B_{2}-8 C_{2}-A_{2}^{3}\right)},
\end{aligned}
$$


the coefficients $A_{2}, B_{2}, C_{2}, D_{2}$ in which are expressed in accordance with formulas $(30-33)$ :

$$
\begin{gathered}
A_{2}=\frac{2 \psi_{p m}}{\left(L_{d}-L_{q}\right)}\left(2-\frac{L_{d}}{L_{q}}\right) \\
B_{2}=\frac{\psi_{p m}^{2}}{\left(L_{d}-L_{q}\right)^{2}}+\frac{4 \psi_{p m}^{2}}{L_{d}\left(L_{d}-L_{q}\right)^{2}}+\frac{\psi_{p m}^{2}}{L_{d}}-\frac{U_{m}^{2}}{\omega_{m e}^{2} L_{d}^{2}}, \\
C_{2}=\frac{2 \psi_{p m}}{L_{d}}\left(\frac{\psi_{p m}^{2}}{\left(L_{d}-L_{q}\right)^{2}}+\frac{\psi_{p m}^{2}}{L_{d}\left(L_{d}-L_{q}\right)}-\frac{U_{m}^{2}}{\omega_{m e}^{2} L_{d}\left(L_{d}-L_{q}\right)}\right), \\
D_{2}=\frac{1}{\left(L_{d}-L_{q}\right)^{2}}\left(\frac{\psi_{p m}^{4}}{L_{d}^{2}}+\frac{4 L_{q}^{2} T_{e}}{9 L_{d}^{2} p}-\frac{U_{m}^{2} \psi_{p m}^{2}}{\omega_{m e}^{2} L_{d}}\right) .
\end{gathered}
$$

The choice of the optimal control algorithm is based on the algorithm shown in Fig. 2. According to Fig. 2, to determine the optimal control algorithm it is necessary to precalculate the values of the boundary parameters, which are $\omega_{0}^{*}, \omega_{n o m}^{*}, \omega_{M T P V}^{*}$, $T_{n o m}^{*}, T_{M T P V}^{*}, T_{M T P V}^{\omega_{r e f}}, T_{M T P A}^{\omega_{r e f}}$ и $T_{M C}^{\omega_{\text {ref }}}$. Conditionally, they can be divided into "static" (parameters that must be calculated once before the algorithm starts working) and "dynamic" (which are calculated every cycle of the control algorithm). The "static" parameters include: $\omega_{0}^{*}, \omega_{n o m}^{*}, \omega_{M T P V}^{*}, T_{n o m}^{*}, T_{M T P V}^{*}$, the "dynamic" are $T_{M T P V}^{\omega_{r e f}}, T_{M T P A}^{\omega_{r e f}}$ and $T_{M C}^{\omega_{\text {ref }}}$.

The parameter $\omega_{0}^{*}$ is the velocity value at which the ellipse obtained according to equation (6) passes through the origin (Fig. 1). For velocities exceeding $\omega_{0}^{*}$, the MTPA control algorithm is no longer optimal.

The $T_{n o m}^{*}$ and $\omega_{\text {nom }}^{*}$ parameters are the nominal PMSM velocity and torque values and are at the intersection of the MTPA curve obtained in accordance with equations $(10-11)$ with the circle bounded by the maximum allowable stator vector amplitude (point " 1 " in Fig. 1).

To determine the values of $T_{M T P V}^{*}$ и $\omega_{M T P V}^{*}$, which are the boundary values of transition from MC mode to MTPV mode, it is necessary to find the point of intersection of the MTPV curve $(23-24)$ with the radius bounded by the vector of maximum stator current amplitude (point " 2 " in Fig. 1). 


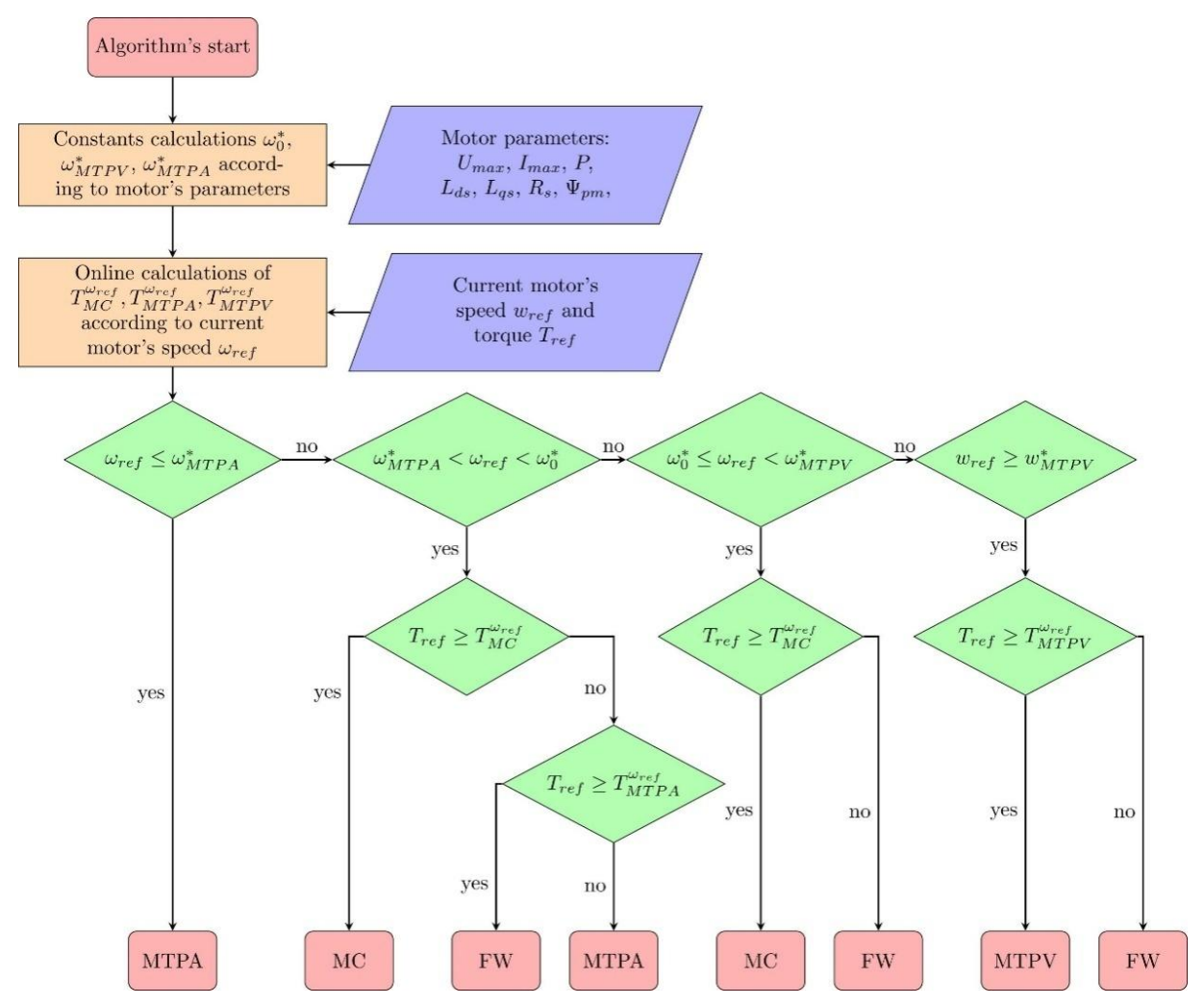

Fig. 2. Diagram for choosing the optimal control algorithm

The $T_{M C}^{\omega_{\text {ref }}}$ parameter is the value of the maximum possible torque at a given speed $\omega_{r e f}$ and is found as the point of intersection of the speed-dependent ellipse (4) with the radius bounded by the vector of maximum stator current amplitude. The value of the torque $T_{M T P A}^{\omega_{\text {ref }}}$ is at the point of intersection of the speed-dependent ellipse according to equation (4) with the MTPA curve obtained according to equations $(10-11)$. Similarly, the value $T_{M T P V}^{\omega_{r e f}}$ is at the point of intersection of the ellipse (4) with the MTPV curve, according to formulas $(23-24)$.

\section{Control system for a permanent magnet synchronous motor with open-endstator winding.}

The topology of the electric drive with the connection of inverters with independent power sources to the beginning and the end of the motor stator windings is shown in Fig. 3. 


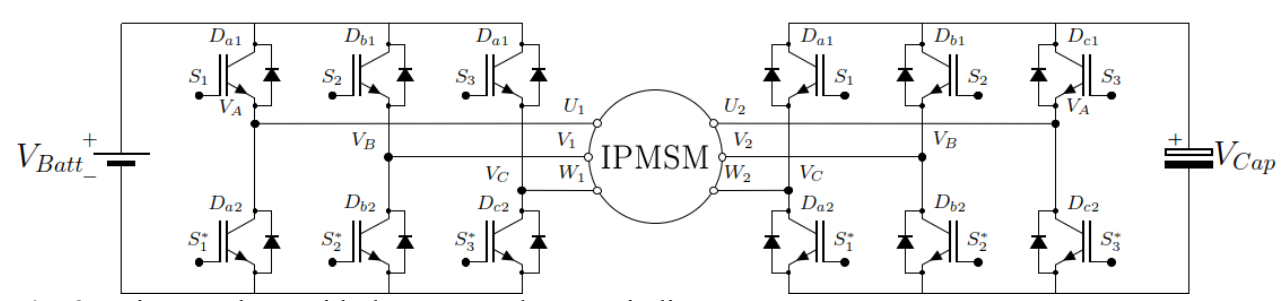

Fig. 3. Drive topology with the open-endstator winding

The resultant value of the voltage with respect to the motor windings will be the potential difference between the connected main and auxiliary source. Based on this, we can write equations (34 - 36):

$$
\begin{gathered}
\vec{U}_{M I}=\vec{U}_{m}+\vec{U}_{C I}, \\
U_{M I d}-U_{m d}-U_{C I d}=0, \\
U_{M I q}-U_{m q}-U_{C I q}=0,
\end{gathered}
$$

where $U_{M I}$ is the traction battery voltage; $U_{C I}$ is the floating bridgecapacitor voltage; $U_{m}$ is the motor winding ends voltage.

Thus, it is necessary to form a voltage vector for the main and auxiliary inverter jointly, the sum of which would result in a generalized voltage vector obtained from the difference of the set and real current values $I_{d}, I_{q}$, multiplied by the coefficients of the corresponding PI regulators.

Fig. 3 shows the vector diagram of the main $U_{M I}$ and auxiliary $U_{C I}$ voltage vectors, which is formed based on the position of the PMSM current vector $I_{m}$ with respect to its voltage vector $U_{m}$. 


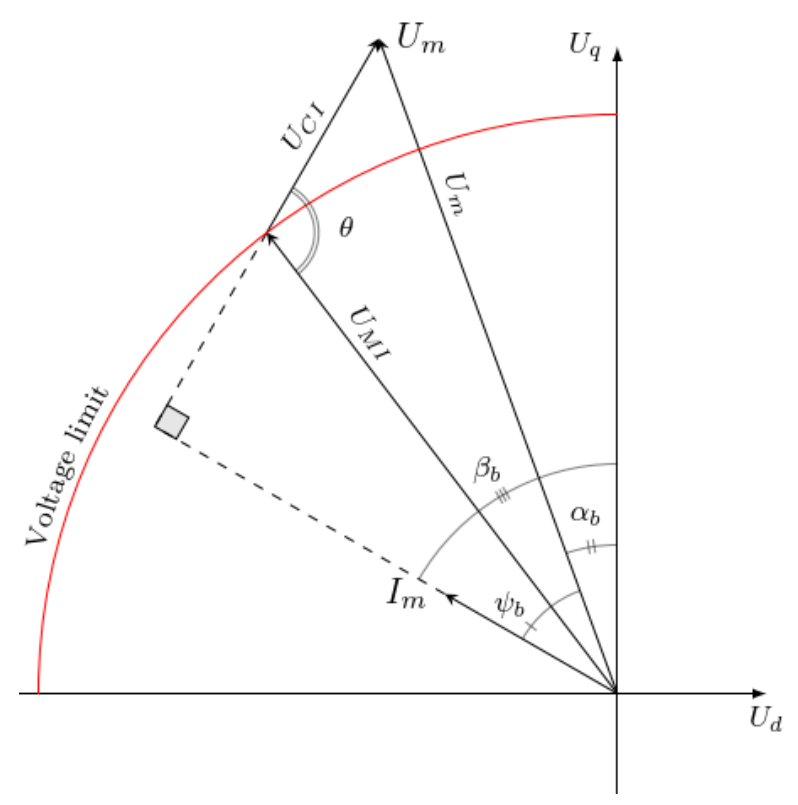

Fig. 4. Open windings PMSM vector diagram

The basic idea of using a floating bridgecapacitor as a power source for the auxiliary inverteris to compensate the counter EMF which is generated by the permanent magnets and depends on the PMSM speed. Thus, to compensate the reactive component by using an auxiliary FC, the voltage vector must be perpendicular to the current vector $I_{m}$. In this case, the voltage source connected to the main FC will be a source of active power only. Therefore, active and reactive power supplied to the electric motor from each of the invertersis regulated by changing the angle of voltage vectors $U_{M I}$ and $U_{C I}$ relative to the stator current vector.

According to the vector diagram shown in Fig. 3, the amplitude of vectors $U_{C I}, U_{M I}$ can be found according to equations $(37-40)$ :

$$
\begin{gathered}
U_{M I}^{d}=U_{m} \cos \left(\psi_{b}\right) \cos \left(\beta_{b}\right)-U_{m}\left(\sin \left(\psi_{b}\right)-U_{\text {react }}\right) \sin \left(\beta_{b}\right), \\
U_{M I}^{q}=U_{m} \sin \left(\psi_{b}\right) \cos \left(\beta_{b}\right)+U_{m}\left(\sin \left(\psi_{b}\right)-U_{\text {react }}\right) \cos \left(\beta_{b}\right), \\
U_{C I}^{d}=U_{\text {cap }}^{\text {set }} \cos \left(\beta_{b}\right)+U_{\text {react }} \sin \left(\psi_{b}\right), \\
U_{C I}^{q}=U_{\text {cap }}^{\text {set }} \sin \left(\beta_{b}\right)-U_{\text {react }} \cos \left(\psi_{b}\right),
\end{gathered}
$$

where $U_{M I}^{d}, U_{M I}^{q}$ is the control voltage setting for aninverter with a connected traction battery; $U_{m}$ is the resulting voltage vector; $U_{C I}^{d}, U_{C I}^{q}$ is the control voltage setting for aninverter with a floating bridgecapacitor; $U_{c a p}$ is the floating bridgecapacitor voltage 
level; $U_{\text {cap }}^{\text {set }}$ is the set value of the capacitor voltage level, which is formed as a ratio of the PI regulator output signal, the input of which is the difference of the set and effective voltage level; $\beta_{b}$ is the current vector $I_{m}$ deflection angle relative to the q-axis of the rotating d-q coordinate system; $\psi_{b}$ is the angle between the current vector $I_{m}$ and the voltage vector $U_{m}$ of the PMSM.

The amplitude of the reactive component of the control voltage vector $U_{\text {react }}$, which can be compensated by the auxiliary inverter, is according to equations $(41-42)$ :

$$
\begin{aligned}
& U_{\text {react }}=k_{d} U_{m} \sin \left(\psi_{b}\right) \text {, if } U_{m} \sin \left(\psi_{b}\right)<U_{\text {cap }} / \sqrt{3}, \\
& U_{\text {react }}=k_{d} U_{\text {cap }} / \sqrt{3} \text {, if } U_{m} \sin \left(\psi_{b}\right) \geq U_{\text {cap }} / \sqrt{3},
\end{aligned}
$$

where $k_{d}$ is the coefficient fixing the position of the vector $U_{m}$ relative to the current vector $I_{m}$ which is equal to " 1 " at values of the angle $\psi_{b} \geq 0$ and " -1 " at values of the angle $\psi_{b}<0$

\section{Simulation modelling}

Simulation modeling was performed using the MATLAB/Simulink software package. A view of the model is shown in Fig. 5.

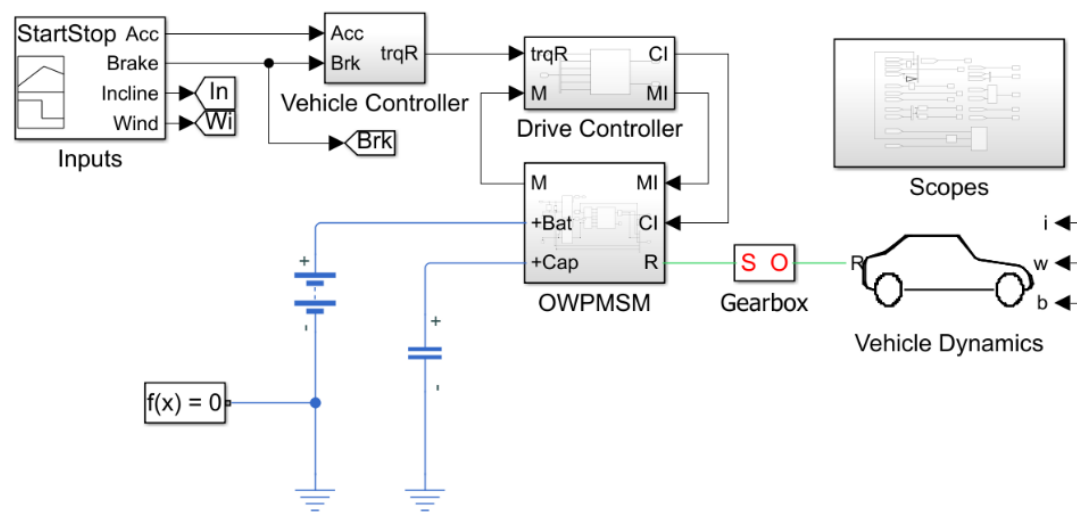

Fig. 5. MATLAB/Simulink model

The main blocks of the model are: "OWPMSM", the simulation block of the PMSM with open stator winding, main and auxiliary IF; "Vehicle Dynamics," the simulation block of vehicle motion dynamics with in-wheel motors, simulation of which was performed in accordance with [37]; "Drive Controller," the block of formation of control impulses for PMSM; "Inputs," the block of formation of the task for acceleration, braking, as well as setting parameters of the roadway slope and the speed of the oncoming wind flow; "Vehicle Controller," the block of formation of the task for the moment based on the data received from the block "Inputs." 
Simulation of the vehicle dynamics was performed using the parameters of the electric car "Nissan Leaf," the characteristics of which are presented in [38]. The main parameters of the simulation model are shown in Table 1. To assess the effectiveness of the proposed topology, the simulation results were compared with the topology having identical parameters of the electric drive, as well as its control system with the connection of the stator winding ends according to the "star" scheme.

Table 1. Values of parameters used for simulation in MATLAB/Simulink

\begin{tabular}{|c|c|c|c|}
\hline Parameter & Symbol & Value & Dimension \\
\hline \multicolumn{4}{|c|}{ Vehicle parameters } \\
\hline Coefficient of rolling friction & $C_{r}$ & 0.008 & - \\
\hline Coefficient of sliding friction & $C_{d}$ & 0.29 & - \\
\hline Frontal area & $A_{f}$ & 2.19 & $m^{2}$ \\
\hline Air density & $\rho_{a}$ & 1.25 & $\mathrm{~kg} / \mathrm{m}^{3}$ \\
\hline Gear ratio & $G$ & 8.2 & - \\
\hline Wheel radius & $R_{w}$ & 0.315 & $m$ \\
\hline Own weight of the vehicle & $m$ & 1521 & $k g$ \\
\hline \multicolumn{4}{|c|}{ Motor parameters } \\
\hline Voltage & $U_{\max }$ & 325 & $V$ \\
\hline Current & $I_{\max }$ & 180 & $A$ \\
\hline Number of pole pairs & $p$ & 8 & - \\
\hline Inductance along the q-axis & $L_{q}$ & 0.297 & $m H$ \\
\hline Inductance along the d-axis & $L_{d}$ & 0.243 & $m H$ \\
\hline Coefficient of capacitance & $\psi_{p m}$ & 0.043 & $W b$ \\
\hline Resistance of the winding & $R_{s}$ & 0.01 & Ohm \\
\hline Moment of inertia of the rotor & $J$ & 0.5066 & $\mathrm{~kg} \cdot \mathrm{m}^{2}$ \\
\hline \multicolumn{4}{|c|}{ Parameters of energy storage devices } \\
\hline Battery voltage & $U_{\text {batt }}$ & 325 & $V$ \\
\hline Capacitor voltage & $U_{c a p}$ & 325 & $V$ \\
\hline
\end{tabular}




\begin{tabular}{|l|l|l|l|}
\hline Capacitance of capacitor & $C$ & 4800 & $\mu F$ \\
\hline
\end{tabular}

Therefore, "Vehicle Dynamics" and "OWPMSM" blocks were simulated according to "Motor parameters" and "Vehicle parameters" data presented in table 1. Battery was simulated with an infinite capacity in order to exclude voltage drop influencing. That's why battery has only voltage parameter. Floating bridge capacitor data described according to "Parameters of energy storage devices" data.

\section{Simulation results}

The simulation results are shown in Fig. 6. According to Fig. 6, it can be noted that the final maximum allowable speed was increased by $1350 \mathrm{rpm}(7700 \mathrm{rpm}$ for the topology using a floating bridgecapacitor versus $6350 \mathrm{rpm}$ for the topology with the connection of stator winding ends according to the "star" scheme). The maximum torque in weak field mode was increased by $10 \mathrm{Nm}$ (60 Nm using the developed topology versus $50 \mathrm{Nm}$ for the standard drive system topology). The PMSM rated speed has also been increased by 800 rpm (2300 rpm for the floating bridgecapacitor topology vs. $1500 \mathrm{rpm}$ for the "star" scheme) to be able to achieve constant torque at the rotor shaft.
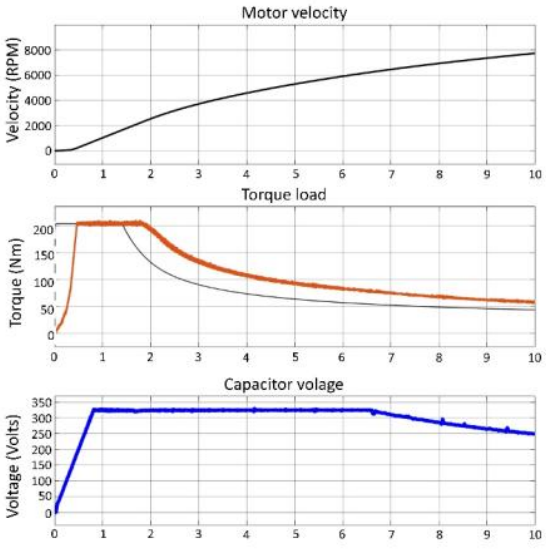

a)
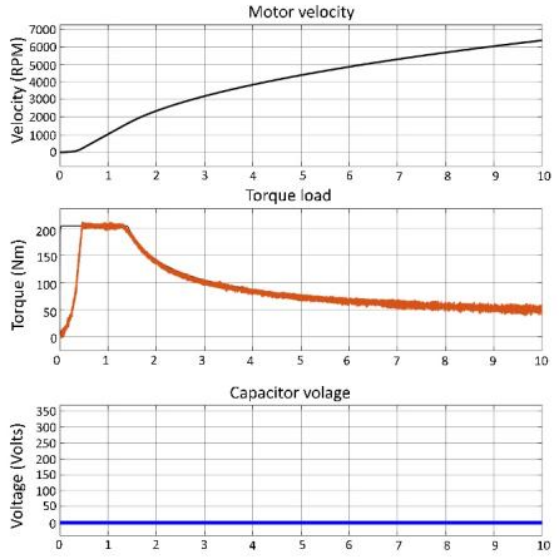

б)

Fig. 6. Diagrams of output characteristics of speed, torque on a shaft, and the capacitor voltage level of the developed and standard topology of electric drive system:

a) Electric drive system with two inverters and a floating bridgecapacitor; b) Electric drive system with one inverter

Fig. 7 shows the change in the driving dynamics of the vehicle. According to the figure, the vehicle using the proposed topology can speed up faster compared to the standard electric drive system topology (acceleration of the electric vehicle to $100 \mathrm{~km} / \mathrm{h}$ using the developed electric drive system took 8 seconds, while the acceleration of electric vehicle using the standard topology exceeds the value of 10 seconds). 


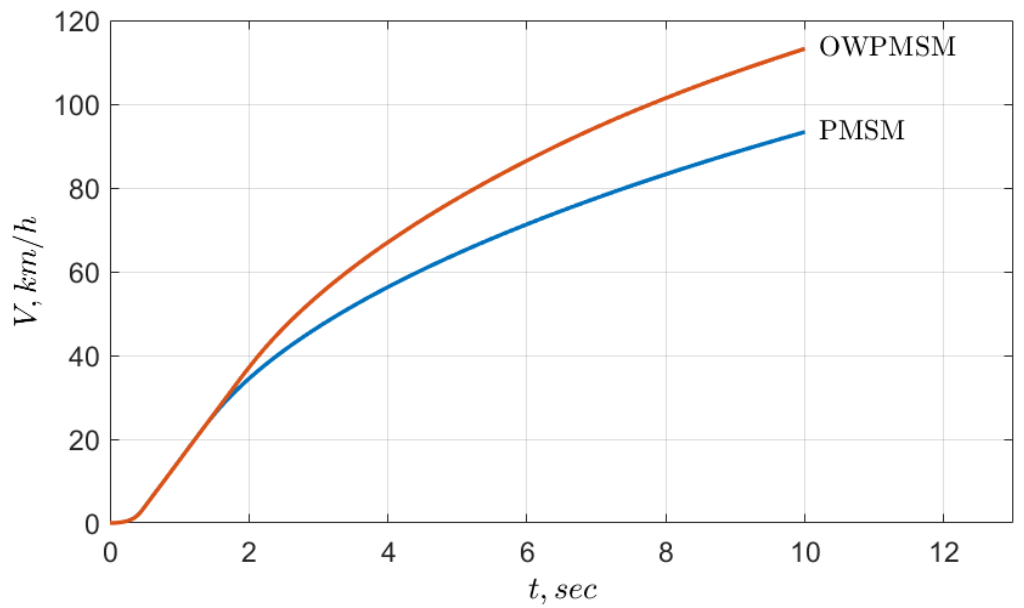

Fig. 7. Vehicle speed when using different electric drive system topologies

\section{Conclusion}

Based on the simulation of the electric drive system for a permanent magnet synchronous motor with a floating bridgecapacitor as a power source for an auxiliary inverter, the following results were achieved:

- A model of an electric drive control system of the proposed topology in Matlab/Simulink environment was developed, a comparative analysis of the proposed topology with the topology of the electric drive with the connection of secondary winding ends according to the "star" scheme was carried out.

- Simulation results showed the possibility of increasing the final speed of the electric motor in the weakened field mode by $17 \%$, while the torque on the rotor shaft increases by $16.6 \%$ compared to the topology of the drive with the connection of the secondary winding ends according to the "star" scheme.

- The use of the developed topology allows increasing the speed range in the mode of constant torque by $34 \%$ compared to the topology of the drive with the connection of the ends of the secondary windings according to the "star" scheme.

\section{Discussion}

Despite the fact that proposed topology helps to achieve torque-speed characteristics for PMSM motor, there are some drawbacks:

- Increasingalgorithmandhardwarecomplexity

- Electricdrive'stotalcostrise

- Doubling the number of IGBT switches

Also, it should be noted that simulations were provided excluding thermal and magnetic losses as well as switching ones. Therefore, further studies will be focused on implementation of proposed topology with finite element modelling of PMSM motor. It will be helpful to calculate overall efficiency of proposed solution. 


\section{References}

1. T. King-Jet, G.H. Chen Computer-Aided Design and Analysis of Direct-Driven Wheel Motor Drive, IEEE Transactions on Power Electronics, 12 (3), 517-27 (1997).

2. C, Lovatt, D. E. Howard, C. Laurence, D. H. Huynh, A. Stumpf, A. Kulkarni, A. Kapoor, et al Design Procedure for Low Cost, Low Mass, Direct Drive, in-Wheel Motor Drivetrains for Electric and Hybrid Vehicles, In IECON 2011 - 37th Annual Conference of the IEEE Industrial Electronics Society, 4558-62 (2011).

3. D. Luque, E. Ruppert, N. Bianchi, M. Castiello Analysis of a Three-Phase in-Wheel Electric Motor, In 2009 44th International Universities Power Engineering Conference (UPEC), 1-5 (2009).

4. A. Benoudjit, N. N. Said New Dual-Airgap Axial and Radial-Flux Induction Motor for on Wheel Drive Electric Propulsion Systems, In POWERCON '98. 1998 International Conference on Power System Technology. Proceedings, 98EX151 (1), 615-19 (1998).

5. A. I. Smirnov, I. N. Voytyuk Diagnostics of Inter-Turn Short-Circuit in the Stator Winding of the Induction Motor, IOP Conference Series: Materials Science and Engineering 643, 012023 (2019). https://doi.org/10.1088/1757-899X/643/1/012023.

6. A. A. Belsky, V. S. Dobush Simulation of a Wind Power Generator Operation as a Part of an Electrotechnical Complex, Journal of Physics: Conference Series 1111, 012051 (2018).

7. Y. Fan, H. Xuedong, X. Zhongbing, J. Hehe Design, Analysis and Control of a Permanent Magnet in-Wheel Motor Based on Magnetic-Gear for Electric Vehicles, In 2011 International Conference on Electrical Machines and Systems, 1-6 (2011).

8. Miyamasu, Masataka, K. Akatsu Efficiency Comparison between Brushless Dc Motor and Brushless AC Motor Considering Driving Method and Machine Design, In IECON 2011 - 37th Annual Conference of the IEEE Industrial Electronics Society, 1830-35 (2011).

9. P.C.K. Luk, P. Jinupun An In-Wheel Switched Reluctance Motor for Electric Vehicles, In 2006 CES/IEEE 5th International Power Electronics and Motion Control Conference, 3, 1-5 (2006).

10. G. Nanda, C. Narayan A Survey and Comparison of Characteristics of Motor Drives Used in Electric Vehicles, In 2006 Canadian Conference on Electrical and Computer Engineering, 811-14 (2006).

11. Stellas, Dimitrios Sensorless Scalar and Vector Control of a Subsea PMSM.

12. X. Wang, Z. Wang, M. Cheng, Y. Hu Remedial Strategies of T-NPC Three-Level Asymmetric Six-Phase PMSM Drives Based on SVM-DTC, IEEE Transactions on Industrial Electronics, 64 (9), 6841-53 (2017).

13. Y. Li, M. Jian, Y. Qiang, L. Jiangyu A Novel Direct Torque Control Permanent Magnet Synchronous Motor Drive Used in Electrical Vehicle, International Journal of Power Electronics and Drive Systems 1 (2), 129 (2011).

14. V. Y. Frolov, R. I. Zhiligotov Development of Sensorless Vector Control System for Permanent Magnet Synchronous Motor in Matlab/Simulink, Journal of Mining Institute, 229, 92-97 (2018).

15. T. Bernardes, V. Montagner, H. Gründling, H. Pinheiro Discrete-Time Sliding Mode Observer for Sensorless Vector Control of Permanent Magnet Synchronous Machine IEEE Transactions on Industrial Electronics 61 (4), 1679-91 (2014). 
16. V. M. Perelmuter Direct torque and current control of AC motors. (Kharkov: Osnova, 2004).

17. J. Kim, S. Sul Speed Control of Interior Permanent Magnet Synchronous Motor Drive for the Flux Weakening Operation, IEEE Transactions on Industry Applications, 33 (1), 43-48 (1997).

18. B. Bae, S. Sul, J. Kwon, J. Byeon Implementation of Sensorless Vector Control for Super-High-Speed PMSM of Turbo-Compressor, IEEE Transactions on Industry Applications, 39 (3), 811-18 (2003).

19. Morimoto, Shigeo, M. Sanada, Y. Takeda, Wide-Speed Operation of Interior Permanent Magnet Synchronous Motors with High-Performance Current Regulator, IEEE Transactions on Industry Applications, 30 (4), 920-26 (1994).

20. D. Pan, K. Huh, T. A. Lipo Efficiency Improvement and Evaluation of Floating Capacitor Open-Winding PM Motor Drive for EV Application, In 2014 IEEE Energy Conversion Congress and Exposition (ECCE), 837-44 (2014).

21. Sun, Dan, Z. Zheng, B. Lin, W. Zhou, M. Chen A Hybrid PWM-Based Field Weakening Strategy for a Hybrid-Inverter-Driven Open-Winding PMSM System, IEEE Transactions on Energy Conversion 32 (3), 857-65 (2017).

22. Lin, Bin, D. Sun Analysis on Constant Power Range Enhancement in Hybrid-Inverter Open Winding PMSM Drive System, In 2014 17th International Conference on Electrical Machines and Systems (ICEMS), 2923-29 (2014).

23. J. Park, N. Kwanghee Dual Inverter Strategy for High-Speed Operation of HEV Permanent Magnet Synchronous Motor, In Conference Record of the 2006 IEEE Industry Applications Conference Forty-First IAS Annual Meeting, 1, 488-94 (2006).

24. J. Hong, L. Heekwang, N. Kwanghee Charging Method for the Secondary Battery in Dual-Inverter Drive Systems for Electric Vehicles, IEEE Transactions on Power Electronics 30 (2), 909-21 (2015).

25. B.A. Welchko A Double-Ended Inverter System for the Combined Propulsion and Energy Management Functions in Hybrid Vehicles with Energy Storage, In 31st Annual Conference of IEEE Industrial Electronics Society, (2005).

26. An, Quntao, J. Liu, Z. Peng, L. Sun, L. Sun Dual-Space Vector Control of Open-End Winding Permanent Magnet Synchronous Motor Drive Fed by Dual Inverter, IEEE Transactions on Power Electronics 31 (12), 8329-42 (2016).

27. Bodo, Nandor, M. Jones, E. Levi A Space Vector PWM With Common-Mode Voltage Elimination for Open-End Winding Five-Phase Drives With a Single DC Supply, IEEE Transactions on Industrial Electronics 61 (5), 2197-2207 (2014).

28. J. Loncarski, M. Leijon, M. Srndovic, C. Rossi, G. Grandi Comparison of Output Current Ripple in Single and Dual Three-Phase Inverters for Electric Vehicle Motor Drives, Energies, 8 (5), 3832-48 (2015).

29. W. Zhou, D. Sun, B. Lin A Modified Flux Weakening Direct Torque Control for Open Winding PMSM System Fed by Hybrid Inverter, In 2014 17th International Conference on Electrical Machines and Systems (ICEMS), 2917-22 (2014). https://doi.org/10.1109/ICEMS.2014.7013995.

30. B. Wang, G. Localzo, G. El Murr, J. Wang, A. Griffo, C. Gerada, T. Cox Overall Assessments of Dual Inverter Open Winding Drives, In 2015 IEEE International Electric Machines Drives Conference (IEMDC), 1029-35 (2015). 
31. M. Carrizosa, N. Stankovic, J. Vannier, Y. E. Shklyarskiy, A. I. Bardanov MultiTerminal Dc Grid Overall Control with Modular Multilevel Converters, Journal of Mining Institute, 243, 357-357 (2020). https://doi.org/10.31897/pmi.2020.3.357.

32. A. A. Belskiy, V. S. Dobush, SH. F. Hajkal Operation of a single-phase autonomous inverter as part of a low-power wind power complex, Journal of Mining Institute, 239, 564-564 (2019).

33. N. Korolev, S. Sergey Monitoring the Technical Condition of Autonomous Electrical Systems with Electric Drive, EDP Sciences, 140, 04015 (2019).

34. D. Casadei, G. Gabriele, A. Lega, C. Rossi Multilevel Operation and Input Power Balancing for a Dual Two-Level Inverter with Insulated DC Sources, IEEE Transactions on Industry Applications, 44 (6), 1815-24 (2008).

35. Y. Lee, J. Ha Hybrid Modulation of Dual Inverter for Open-End Permanent Magnet Synchronous Motor, IEEE Transactions on Power Electronics, 30 (6), 3286-99 (2015).

36. G. Hayes, K. Davis Simplified Electric Vehicle Powertrain Model for Range and Energy Consumption Based on EPA Coast-down Parameters and Test Validation by Argonne National Lab Data on the Nissan Leaf, In 2014 IEEE Transportation Electrification Conference and Expo (ITEC), 1-6 (2014).

37. G. Hayes, G. A. Goodarzi Electric Powertrain: Energy Systems, Power Electronics and Drives for Hybrid, Electric and Fuel Cell Vehicles. (John Wiley \& Sons, 2018). 